\title{
PHYSICO-CHEMICAL PROPERTIES OF MAGNESIUM IONIC LIQUID ANALOGOUS
}

\author{
HUAIYOU WANG ${ }^{a, b}$, YONGZHONG JIA ${ }^{a}$, XIAOHUA WANG ${ }^{a}, J U N M A^{a}, Y_{A N} J I N G^{a, *}$ \\ ${ }^{a}$ Qinghai Institute of Salt Lakes, Chinese Academy of Sciences, 810008, Xining, China. \\ ${ }^{b}$ Graduate University of Chinese Academy of Sciences, 100049, Beijing, China.
}

(Received: September 5, 2011 - Accepted: May 8, 2012)

\begin{abstract}
In this paper, the solubility of Choline chloride $(\mathrm{ChCl})$ in ethylene glycol $(\mathrm{EG})$ was measured by isothermal method in the temperature range between $0^{\circ} \mathrm{C}$ and $120^{\circ} \mathrm{C}$. The solubility of $\mathrm{MgCl}_{2}$ in saturated $\mathrm{ChCl}$-EG mixture was measured by isothermal method at $20^{\circ} \mathrm{C}, 50^{\circ} \mathrm{C}$ and $70^{\circ} \mathrm{C}$, respectively. Ionic liquid analogous containing $\mathrm{MgCl}_{2}$ was prepared based on the measured solubility data. The structure of the ionic liquid analogous is preliminarily investigated by Fourier transform infrared spectroscopy. The physical and electrochemical properties of the ionic liquid such as viscosity, conductivity, molar conductivity and density were measured as function of temperature and compositions. It was found that magnesium ionic liquid analogous was highly conducting and low viscosity. The $\mathrm{ChCl}$ and $\mathrm{MgCl}_{2}$ had a great effect on the studied properties.
\end{abstract}

Keywords: ionic liquid; magnesium ionic liquid analogous; physical properties; electrochemical properties;

\section{INTRODUCTION}

The main applications of magnesium salts are to produce magnesium and its alloys. Some researchers were making effort to develop electrolyte solutions in which $\mathrm{Mg}\left(\mathrm{ClO}_{4}\right)_{2}, \mathrm{Mg}\left(\mathrm{CF}_{3} \mathrm{SO}_{3}\right)_{2}, \mathrm{Mg}\left[\left(\mathrm{CF}_{3} \mathrm{SO}_{2}\right)_{2} \mathrm{~N}\right]_{2}$ and Grignard reagent were used as magnesium source to synthesize a variety of imidazolium ionic liquids ${ }^{1-4}$. A magnesium-based ionic liquid with wide electrochemistry window was reported ${ }^{2}$. The highly reversible magnesium deposition and dissolution processes on silver substrate in the ionic liquid were described. Moreover, investigation has been developed to deposit magnesium from room temperature ${ }^{5-6}$. But deep eutectic solvent has recently been considered as alternatives to classical ionic liquids ${ }^{7}$. Room temperature molten salts have been formed by mixing quaternary ammonium salts with metal salts ${ }^{8}$. Since Deep eutectic solvent (DES) possess the same chemical and physical properties with ionic liquids, such as large liquid temperature ranges, high ionic conductivities, and wide electrochemical window ${ }^{9-11}$, it seems appropriate to classify them as ionic liquids analogous. Works in this area focused on $\mathrm{ChCl}$ / $\mathrm{ZnCl}_{2}^{7,12,13}$, ChCl/urea ${ }^{9}, \mathrm{ChCl} / \mathrm{CrCl}_{3} \bullet 6 \mathrm{H}_{2} \mathrm{O}^{14}$ ionic liquid analogous. Abbott has recently developed a range of ionic compounds which are fluid at room temperature. These ionic liquids are based on simple precursors such as $\mathrm{ChCl}$ (vitamin B4) which is cheap. Using these liquids, a number of applications are now under development such as electrodeposition of metals, synthesis of cadmium and zinc semiconductor compounds and so on. The electrodeposition of chromium in a mixture of $\mathrm{ChCl}$ and chromium (III) chloride hexahydrate has been reported recently ${ }^{14}$. These studies suggest that choline cations can substitute for synthetic cations. Ionic liquids based on $\mathrm{ChCl}$ has the additional advantage to be easy to prepare, to be water and air stable, which enable their use in large scale applications. Choline is a naturally occurring biocompatible compound if it was released back to nature. These will provide evidence for the change in properties of ionic liquid. But many physical properties such as viscosity, conductivity, molar conductivity and density of magnesium ionic liquid analogous are few reported.

In this paper, we reported a method of synthesis and characterization of novel air and moisture stable ionic liquids made from magnesium chloride choline chloride and EG. These offer the potential to tailor the physical properties such as melting point, viscosity and conductivity. The advantages of these new ionic liquids over presently available magnesium-containing ionic liquids are moisture stable and much cheaper than imidazolium-based liquids.

\section{EXPERIMENTAL SECTION}

$\mathrm{ChCl}\left[\mathrm{HOC}_{2} \mathrm{H}_{4} \mathrm{~N}\left(\mathrm{CH}_{3}\right)_{3}{ }_{3} \mathrm{Cl}^{-}\right]$(Aldrich,99\%, Sinopharm chemical Reagent Co., Ltd, China) was, when necessary, recrystallised from absolute ethanol, filtered and dried under vacuum. Ethylene glycol (EG) (Aldrich 99+\%, Tianjin Baishi Chemical Co., Ltd, China), was used as received. Magnesium chloride $\left(\mathrm{MgCl}_{2}\right)$ (Aldrich 99+\%, Tianjin Baishi Chemical Co., Ltd, China) was used as received.

The $\mathrm{ChCl}$ were gradually added in $\mathrm{EG}$ in a round bottom flask with three necks until $\mathrm{ChCl}$ was not dissolved in the temperature range between $0^{\circ} \mathrm{C}$ and $120^{\circ} \mathrm{C}$. The variation of the temperature was done by using a water-bath with temperature control and mechanical stirrer.
$\mathrm{ChCl}$ and EG in a molar ratio of 2:5; 7:10;1:1(saturated) were combined and heated at $20^{\circ} \mathrm{C}, 50^{\circ} \mathrm{Cand} 70^{\circ} \mathrm{C}$, respectively by Collector-type magnetic heating stirrer. Follow above steps, the $\mathrm{MgCl}_{2}$ was gradually added in liquid until $\mathrm{MgCl}_{2}$ was not dissolved and a homogeneous liquid was formed. All synthesis procedures were done at atmospheric pressure. The viscosity, conductivity, density and Cyclic Voltammetry curves (CV) were measured by different instrument when $\mathrm{MgCl}_{2}$ was added in ChCl-EG each time.

Fourier transform infrared spectroscopy (FTIR) analysis was carried out by a Nicolet Nexus 670 FTIR Spectrophotometer (Thermo Nicolet Corporation, Madison, USA) in liquid films using $\mathrm{KBr}$ salt tablets.

The viscosity of magnesium ionic liquid analogous was determined using a rotary (NDJ-1 shanghai yueping scientific instrument Co.,Ltd, China) viscometer. The variation of the temperature was done by using a water-bath with temperature control.

The conductivity and its temperature dependence was measured using shanghai scientific instrument Co., Ltd conductivity meter with temperature and conductivity probes. The variation of the temperature was done by using a water-bath with temperature control.

Cyclic voltammetry were obtained using CS310 electrochemical workstation (WuHan CorrTest Instrument Co.Ltd.). A three-electrode electrochemical cell was used for the electrochemical experiments system consisting of an $\mathrm{Ag}$ wire; a platinum wire counter electrode and a platinum wire reference electrode were used. The working electrode was polished with sandpaper, rinsed and dried prior to all measurements. Electrochemical measurements were performed at $20^{\circ} \mathrm{C}, 50^{\circ} \mathrm{C}, 70^{\circ} \mathrm{C}$ and a scan rate of $20 \mathrm{mV} \mathrm{s}^{-1}$ was used in voltammetric experiments.

\section{RESULTS AND DISUSSION}

\section{The solubility of $\mathrm{ChCl}$ in $\mathrm{EG}$}

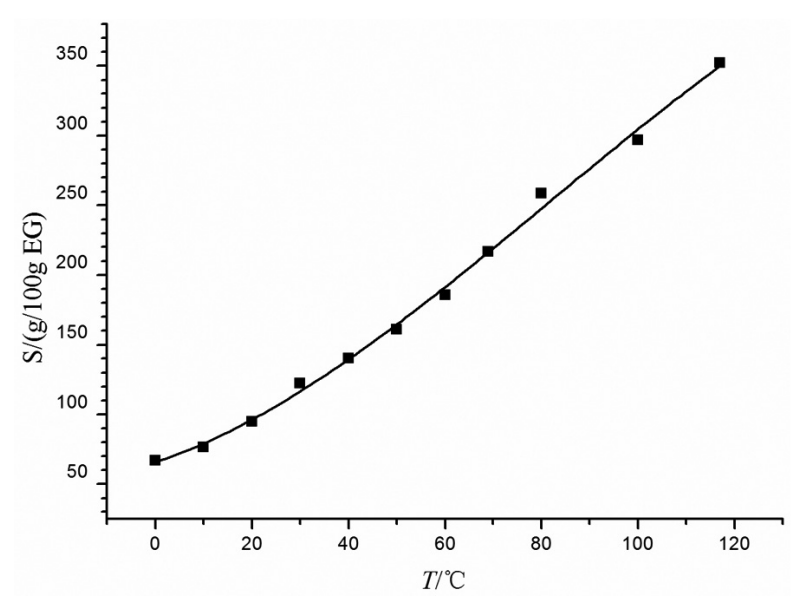

Figure 1 The solubility of $\mathrm{ChCl}$ in $\mathrm{EG}$ as a function of temperature. 
Figure 1 shows the solubility of $\mathrm{ChCl}$ in $\mathrm{EG}$ as a function of temperature. It is noticeable that the solubility of $\mathrm{ChCl}$ in $\mathrm{EG}$ is considerably high. The solubility of the medium is increasing as the increasing temperature.

Table 1 The solubility of $\mathrm{MCl}_{2}$ in $\mathrm{ChCl}-\mathrm{EG}$ saturated mixture at $20^{\circ} \mathrm{C}$, $50^{\circ} \mathrm{C}, 70^{\circ} \mathrm{C}$, respectively.

\begin{tabular}{|c|c|}
\hline $\mathrm{T} /{ }^{\circ} \mathrm{C}$ & $\mathrm{m}_{\mathrm{MgCl} 2} / \mathrm{g}$ \\
\hline 20 & 2.024 \\
\hline 50 & 3.669 \\
\hline 70 & 4.755 \\
\hline
\end{tabular}

Table 1 shows the solubility of $\mathrm{MCl}_{2}$ in $\mathrm{ChCl}$-EG saturated mixture at $20^{\circ} \mathrm{C}, 50^{\circ} \mathrm{C}, 70^{\circ} \mathrm{C}$, respectively. It is noticeable that the solubility of $\mathrm{MCl}_{2}$ in ChCl-EG saturated mixture considerably decrease compared to $\mathrm{MgCl}_{2}$ in $\mathrm{EG}$ (table 2), which can attribute to salting out effect of $\mathrm{MgCl}_{2}$ and $\mathrm{ChCl}$.

Table 2 The solubility of $\mathrm{MCl}_{2}$ in EG saturated at $20^{\circ} \mathrm{C}, 50^{\circ} \mathrm{C}, 70^{\circ} \mathrm{C}$, respectively.

\begin{tabular}{|c|c|}
\hline $\mathrm{T} /{ }^{\circ} \mathrm{C}$ & $\mathrm{m}_{\mathrm{MgCl} 2} / \mathrm{g}$ \\
\hline 20 & 8.492 \\
\hline 50 & 15.344 \\
\hline 70 & 17.833 \\
\hline
\end{tabular}

\section{FTIR}

Fourier transform infrared spectroscopy (FTIR) is used to study the interaction between different groups, analyze and identify structures. Frequency shifts, band widths and absorbance values of the same bond in different systems are used to interpret the structure of the ionic liquid.

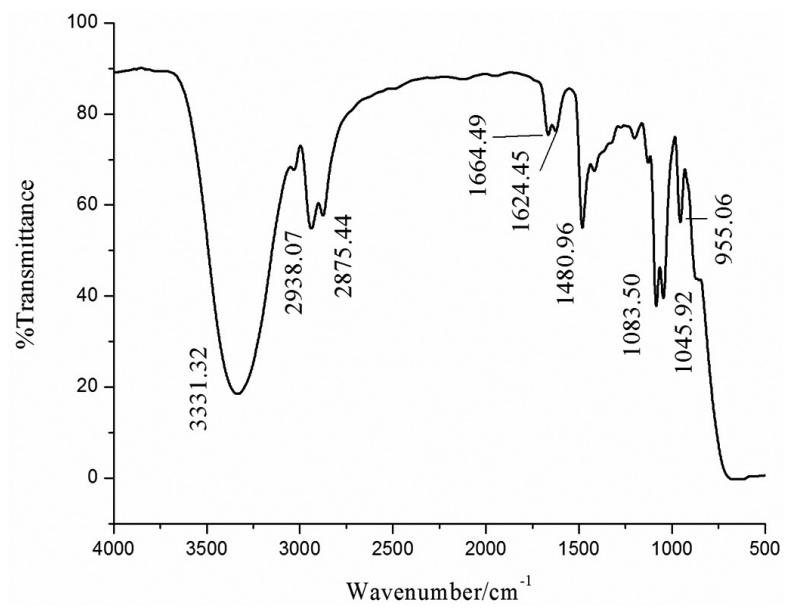

Figure 2. The FTIR spectra of $\mathrm{ChCl}-\mathrm{EG}-\mathrm{MgCl}_{2}$ ionic liquid analogous

Figure 2 is the FTIR spectroscopy of ionic liquids analogous ChCl-EG$\mathrm{MgCl}_{2}$. The broad peak between 3500 and $3000 \mathrm{~cm}^{-1}$ in figure 2 shows the hydrogen bond forming in ionic liquids analogous. The hydrogen bonds formed in system ChCl-EG-MgCl is the $\mathrm{H}-\mathrm{O} . . . \mathrm{H}$. The weak peak between 2875 and $2940 \mathrm{~cm}^{-1}$ in the figure 2 also shows the hydrogen bonds H-O...H exist. In the ionic liquid analogous systems, it can be noted the $v_{\mathrm{CC}}$ at $955.31 \mathrm{~cm}^{-1}, 955.06$ $\mathrm{cm}^{-1}, 958.98 \mathrm{~cm}^{-1}$ associated to $\mathrm{ChCl}$. Compared with $\mathrm{ChCl}$ (The FTIR spectra of $\mathrm{ChCl}$ is not listed), the frequency of $v_{\mathrm{CC}}$ is not changed which indicates the structure of $\mathrm{Ch}^{+}$is not destroyed.

\section{Viscosity}

Viscosity is an important property of ionic liquids used as electrolyte solutions and low viscosity of ionic liquid is expected. The viscosity of ionic liquids is determined by Vander Waals forces and hydrogen bonding. Electrostatic forced may also play an important role.

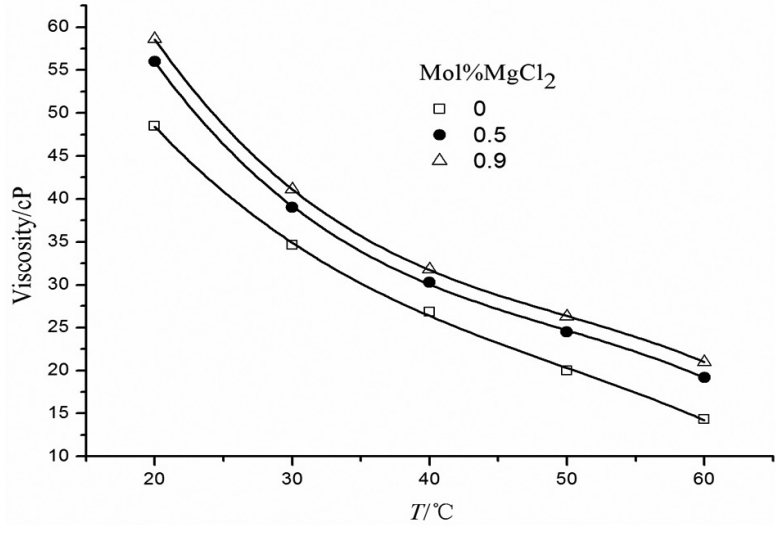

Figure 3 The viscosities of $\mathrm{ChCl}$-EG- $\mathrm{MgCl}_{2}$ mixtures as a function of temperature and compositions.

Figure 3 shows the viscosity of $\mathrm{ChCl}-\mathrm{EG}-\mathrm{MgCl}_{2}$ mixtures as a function of temperature and compositions. It is noticeable that the viscosity of ChCl-EG$\mathrm{MgCl}_{2}$ covers the range 10 to $60 \mathrm{cp}$. The minimum viscosity is not observed at the eutectic composition. The viscosity of $\mathrm{ChCl}-\mathrm{EG}-\mathrm{MgCl}_{2}$ mixtures decreases with the increasing temperature and increases as the increasing mole fraction of $\mathrm{MgCl}_{2}$, which can attribute to the high temperature leads the Van Der Waals Force between different groups change to weak. Halide salts can also form complexes with hydrogen bond honors. ${ }^{15}$ When more $\mathrm{MgCl}_{2}$ are added, the numbers of molecules in per unit volume increase which leads to the Van Der Waals Force between different groups become stronger. It also can be concluded that maybe $\mathrm{MgCl}_{2}$ play the role of bridge that connect the other ionic groups. As more $\mathrm{MgCl}_{2}$ are added, more bridges are built. Then the network between different groups is formed. Since the formation of network structure, viscosity increases.

It also shows that the viscosity of these ionic liquids is considerably lower than ionic liquid analogous based on $\mathrm{ChCl}$ reported previously ${ }^{14}$ and are similar to those for most imidazolium based ionic liquids reported previously ${ }^{1,15,16}$ suggesting that the $\mathrm{H}$-bonds played a significant role in magnesium ionic liquid analogous.

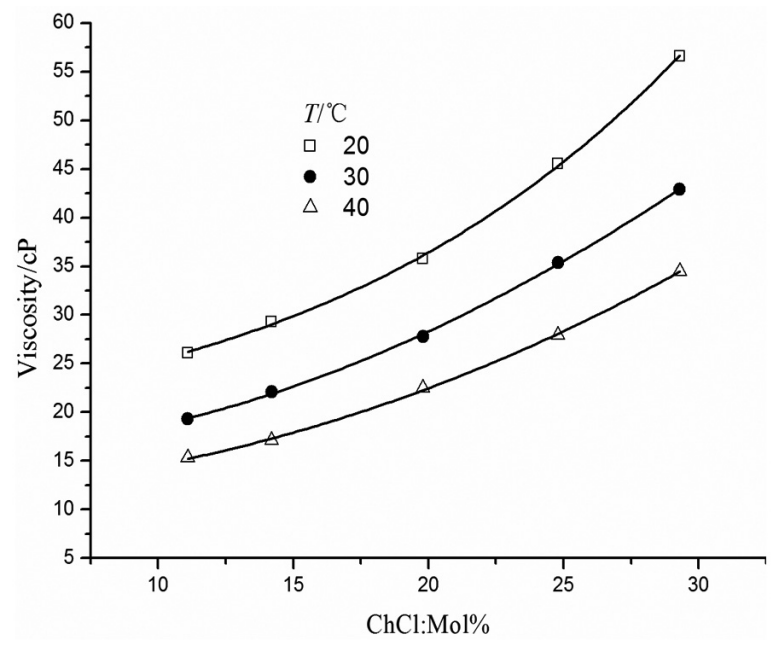

Figure 4 The viscosities of $\mathrm{ChCl}-\mathrm{EG}-\mathrm{MgCl} 2$ mixtures as a function of $\mathrm{ChCl}$.

Figure 4 shows the viscosity of $\mathrm{ChCl}-\mathrm{EG}-\mathrm{MgCl}_{2}$ mixtures as a function of $\mathrm{ChCl}$. It is noted that the viscosity increased as the salt is added in the mixture. This is because the diols form linear aggregates of hydrogen-bonded molecules. The change in viscosity (h) with temperature is given by Equation (1):

$$
\ln \eta=\ln \eta_{0}+\frac{E_{\eta}}{R T}
$$


In which $\eta_{0}$ is a constant, $E$ is the energy for activation of viscous Flow ${ }^{16}$ and $\mathrm{R}$ is the gas constant. Table 3 shows that all the data in figure 3 it well to Equation (1). The values obtained for $E_{\eta}$ helps with the design of low viscosity ionic fluids.

Table 3 Activation energies for viscous flow $\left(E_{n}\right)$ and conductivity $\left(E_{A}\right)$ as a function of liquid composition. Coefficients of correlation (r) for the fits to Equations (1) and (2) are also given.

\begin{tabular}{|c|c|c|c|c|}
\hline $\begin{array}{c}\mathrm{ChCl} / \mathrm{EG} / \\
\mathrm{MgCl}_{2}\end{array}$ & $\mathrm{E}_{\eta}\left[\mathrm{kJ} \times \mathrm{mol}^{-1}\right]$ & $\mathrm{r}$ & $\mathrm{E}_{\Lambda}\left[\mathrm{kJ}^{-1} \times \mathrm{mol}^{-1}\right]$ & $-\mathrm{r}$ \\
\hline $2: 5: 0$ & 292.1 & 0.933 & 473.2 & -0.998 \\
\hline $2: 5: 0.035$ & 244.0 & 0.969 & 295.0 & -0.958 \\
\hline $2: 5: 0.06$ & 238.7 & 0.972 & 284.9 & -0.957 \\
\hline
\end{tabular}

\section{Conductivity}

The conductivity of ionic liquids is inversely linked to their viscosity. Hence, ionic liquids of higher viscosity exhibit lower conductivity. Deep eutectic solvents are highly conducting (ca. $8.74 \mathrm{mScm}^{-1}$ at $20^{\circ} \mathrm{C}$ ) ${ }^{15}$, confirming that the ionic species are dissociated in the liquid and can move independently. The viscosity and conductivity are strongly affected by quaternary ammonium salt and hence the fluid properties could be tailored for specific applications.

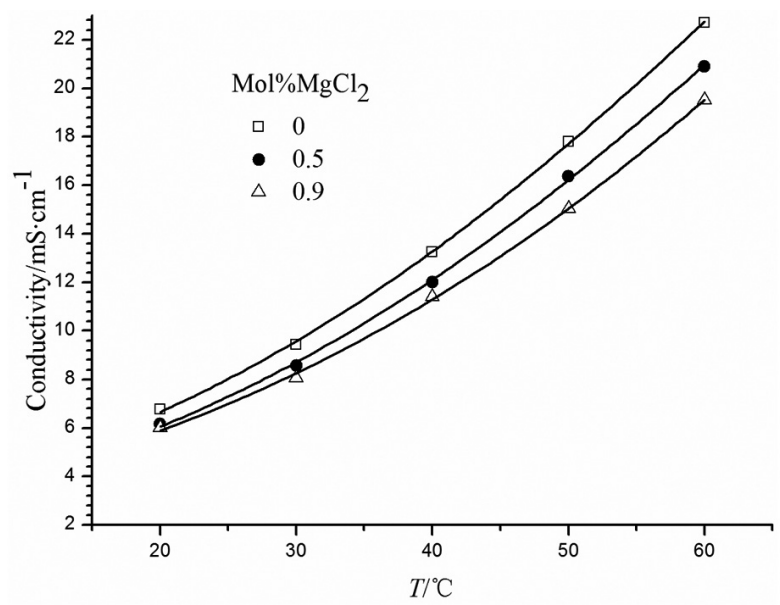

Figure 5 Conductivity of $\mathrm{ChCl}-\mathrm{EG}-\mathrm{MgCl}_{2}$ mixtures as a function of temperature and compositions.

Figure 5 shows the conductivity of $\mathrm{ChCl}$-EG- $\mathrm{MgCl}_{2}$ mixtures as a function of temperature and compositions. It is noticeable that the conductivity of $\mathrm{MgCl}_{2}$-EG-ChCl covers the range 5.99 to $22.7 \mathrm{mS} \cdot \mathrm{cm}^{-1}$. The conductivity inconsiderably decreases with the increasing $\mathrm{MgCl}_{2}$. For ionic liquids the conductivity is generally governed by the mobility of the charge carrier. Charge carrier decreases with the increasing $\mathrm{MgCl}_{2}$, which is probably the formation of complex between $\mathrm{MgCl}_{2}$ and $\mathrm{EG}$ when $\mathrm{MgCl}_{2}$ is added in the liquid. The large constituent ions of ionic liquids reduced the ion mobility which, in turn, leads to lower conductivities. Furthermore, ion pair formation and/or ion aggregation lead to reduced conductivity. Values are similar to those for most imidazolium based ionic liquids and two orders of magnitude larger than for the choline chloride-zinc chloride system previously studied ${ }^{13}$. This is probably related to the viscosity of the ionic liquid, since the viscosity of $\mathrm{MgCl}_{2}$-EG-ChCl shown in figure 3 is similar to that of imidazolium ionic liquid and smaller than ChCl-urea ${ }^{9}$. Comparison between figure 3 and figure 5 , it can be noted that the conductivity decreases with the increase of viscosity in the same compositions. This may be result from the high viscosity prevents the movement of ions. Abbott and co-worker reported the highest conductivity of ChCl-EG ionic liquid analogous at the molar ratio of 1:4 ${ }^{18}$.

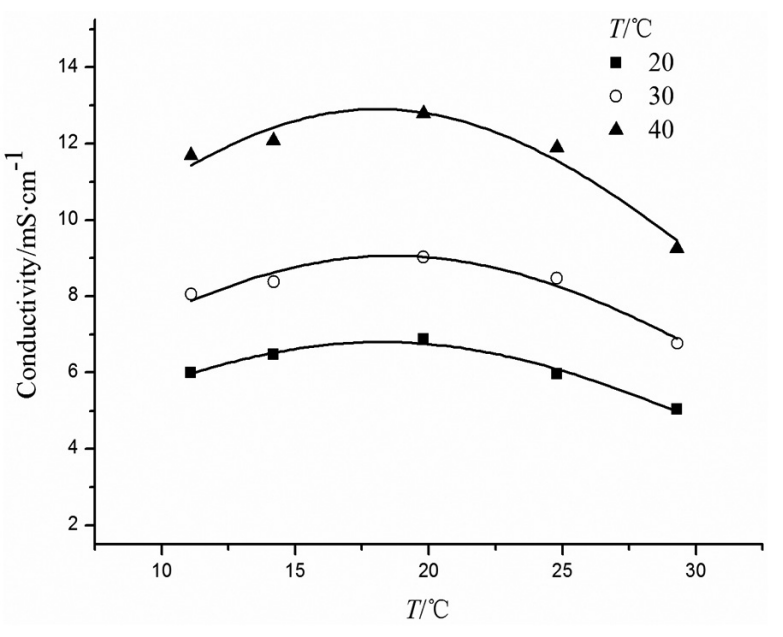

Figure 6 The conductivity of $\mathrm{ChCl}-\mathrm{EG}-\mathrm{MgCl}_{2}$ as a function of $\mathrm{ChCl}$.

Figure 6 shows the conductivity of $\mathrm{ChCl}-\mathrm{EG}-\mathrm{MgCl}_{2}$ as a function of $\mathrm{ChCl}$. It is noticeable that the conductivity of $\mathrm{ChCl}-\mathrm{EG}-\mathrm{MgCl}_{2}$ is the highest at the mole ratio 2:8:0.06. Analogous to the viscosity data, conductivity (s) of ionic liquids has been fitted to Equation (2) ${ }^{16}$

$$
\ln \sigma=\ln \sigma_{0}-\frac{E_{\Lambda}}{R T}
$$

The activation energy for conduction $\left(E_{\mathrm{A}}\right)$ is listed in Table 3 as a function of composition. As for the $E_{\text {values, }}$ they are significantly larger than choline chloride $/ \mathrm{CrCl} 2 \bullet 6 \mathrm{H} 2 \mathrm{O}$ ionic liquid analogous (values from 37.8 to 50.5$)^{14}$

The molar conductivity was calculated by $(3)^{19}$

$$
\Lambda=\kappa M / \rho
$$

Where $\kappa$ is the conductivity, $\rho$ is the density, and $M$ is the molar mass which is taken as being the molar mass of the three components multiplied by their mole fraction in the mixtures. It is noted that mole conductivity firstly increases, then decreases with the increasing $\mathrm{ChCl}$ and decreases as the increasing $\mathrm{MgCl}_{2}$. This is consistent with the trend of conductivity. At low concentrations, most of the ions exist as ion pairs, and the molar conductivity is relatively low. The molar conductivity increases as the concentration of triple ion increases according to occur in non-aqueous solutions ${ }^{18}$.

$$
3 \mathrm{ChCl} \mathrm{Ch}_{2} \mathrm{Cl}^{+}+\mathrm{ChCl}_{2}^{-}
$$

The molar conductivity is inversely proportional to the viscosity of ionic liquid and this correlation is virtually independent of the cation and anion. This has been used as a method of defining the properties of an ionic liquid ${ }^{18}$.

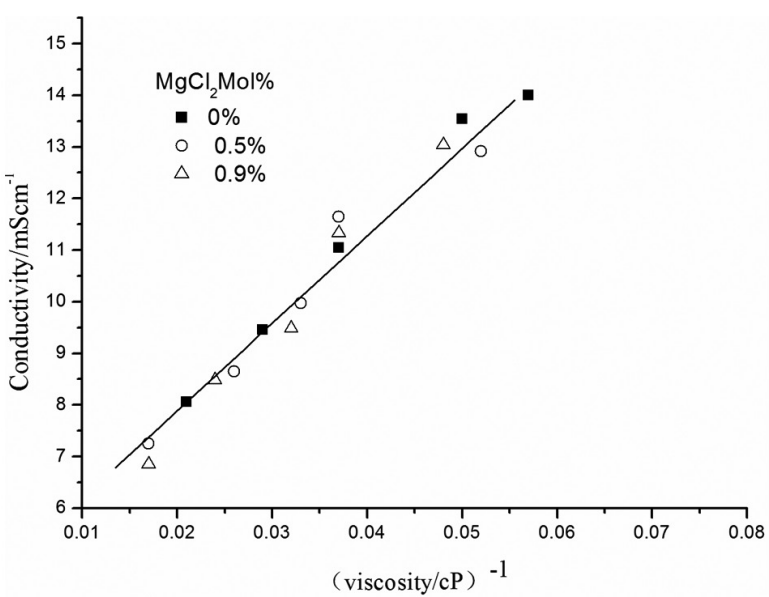

Figure 7 Conductivity as a function of $1 /$ viscosity for the data in Figures 3 and 5 . 
Figure 7 shows a strong linear correlation between conductivity and the reciprocal of viscosity, which shows that the ionic mobility is controlling the conductivity of the liquid. It also shows that since the slope is approximately constant at all compositions, the charge-carrying species is dominated by one species $^{18}$.

The relatively high conductivities of magnesium ionic liquid analogous make them good candidates for electrochemical applications, such as electrodeposition, electrofinishing.

\section{Cyclic Voltammetry curves}

The clear application of ionic liquid analogous containing magnesium is for the study of magnesium electrodeposition. And reduction potential of the electrolyte solution is one of the important properties. The reduction potential is governed not only by the chemical structure of the materials used but also by the electrode materials, sweep rate of the potential, temperature, solvent, impurity and so on.
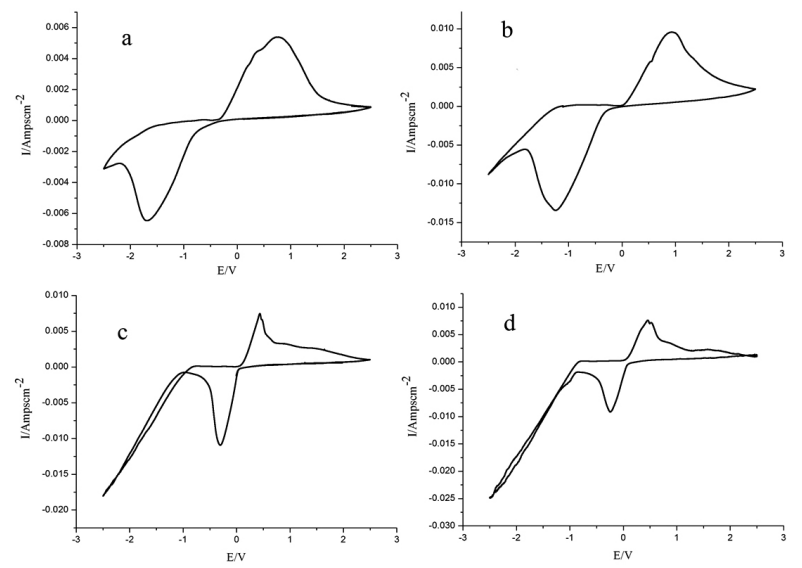

Figure 8 The $\mathrm{CV}$ curves as a function of temperature and compositions. $\mathrm{X}$ $\left(\mathrm{MgCl}_{2}\right)$ :a $0.3, \mathrm{~b} 0.8$ at $20^{\circ} \mathrm{C}, \mathrm{c} 1.1$ at $50^{\circ} \mathrm{C}, \mathrm{d} 0.8$ at $70^{\circ} \mathrm{C}$.

Figure 8 shows the $\mathrm{CV}$ curves as a function of temperature and compositions on an $\mathrm{Ag}$ wire at a sweep rate of $20 \mathrm{mV} \times \mathrm{s}^{-1}$. As can be seen from the figure 8.a the peak reduction potentials for magnesium is about $-1.8 \mathrm{~V}$. Figure 8.b,c,d show the peak reduction potentials for magnesium are very similar in different components $\mathrm{MgCl}_{2}$ based liquids in the same temperature $\left(50^{\circ} \mathrm{C}, 70^{\circ} \mathrm{C}\right)(-0.315 \mathrm{~V}$ and $-0.474 \mathrm{~V}$, respectively). But The peak reduction potentials for magnesium is great changing from $-0.88 \mathrm{~V}$ to $-1.66 \mathrm{~V}$ at $20^{\circ} \mathrm{C}$. The large reduction peak at $-1.66 \mathrm{~V}$ at $20^{\circ} \mathrm{C}$ is probably due to reduction of the magnesium cation. It is clear that the reduction process does not produce an entirely adherent deposit, because the charge of the anodic process is much less than that of the cathodic process.

\section{Density}

The variation ratio of magnesium ionic liquid analogous density with temperature is shown in figure 9 .

$$
\rho / \mathrm{g} \cdot \mathrm{cm}^{-3}=a\left(t /{ }^{\circ} \mathrm{C}\right)+b
$$

Where $\rho$ is the density, $\mathrm{t}$ is the temperature, $a$ and $b$ are a constant that depends on the type of magnesium ionic liquid analogous. The values of $a$ and $b$ for the tested magnesium ionic liquid analogous are shown in Table 4 .

Table 4 Values of Parameters a and b Used in Equation 5.

\begin{tabular}{|c|c|c|}
\hline $\mathrm{ChCl} / \mathrm{EG} / \mathrm{MgCl}_{2}$ & $\mathrm{a}$ & $\mathrm{b}$ \\
\hline $2: 5: 0$ & $-5.25 * 10^{-4}$ & 1.1322 \\
\hline $2: 5: 0.035$ & $-5.57 * 10^{-4}$ & 1.1385 \\
\hline $2: 5: 0.06$ & $-5.23 * 10^{-4}$ & 1.1396 \\
\hline
\end{tabular}

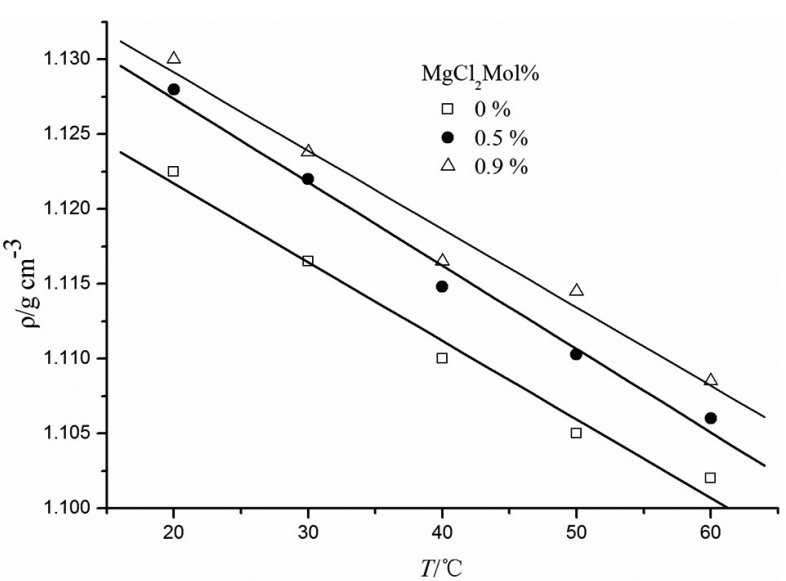

Figure 9 Densities of magnesium ionic liquid analogous as a function of temperature.

The behavior here is linear as expected. The results for these magnesium ionic liquid analogous are fitted by a linear relationship as follows ${ }^{19}$ :

\section{CONCLUSION}

Solubility of chiline chloride was first surveyed in ethylene glycol (EG) and the solubility of $\mathrm{MgCl}_{2}$ was acquired in saturated ChCl-EG. Magnesium ionic liquid analogous has been synthesized by mixing choline chloride with magnesium chloride and Ethylene glycol. Physico-chemical properties were experimentally measured for this novel magnesium ionic liquid analogous.

Fourier transform infrared spectroscopy shows that the hydrogen bond forming in ionic liquids analogous. It was found that the type of ionic liquid was low viscosity, high ionic conductivity. The effect of temperature and compositions on the measured physical properties was discussed in detail. The viscosity of $\mathrm{ChCl}-\mathrm{EG}-\mathrm{MgCl}_{2}$ decreased with the increasing temperature and increased as the increasing mole fraction of $\mathrm{MgCl}_{2}$. The conductivity of $\mathrm{MgCl}_{2}$-EG-ChCl inconsiderably decreased with the increasing $\mathrm{MgCl}_{2}$. The conductivity was the highest at the mole ratio 2:8:0.06 at the same temperature. A straight line equation was used to fit the density while Arrhenius equation was used to fit both viscosity and conductivity profiles. Cyclic voltammetry showed that the peak reduction potentials for magnesium is lower than standard reduction potentials of magnesium $(-2.37 \mathrm{~V})$.

\section{ACKNOWLEDGEMENTS}

This work is financially supported with the Major Project of Chinese National Programs for Fundamental Research and Development (973 Preprogram, No. 2010CB635100), General Project of Natural Science Foundation of China (No. 201073217) and Natural Science Foundation of Qinghai (No. 2011-2-931Q).

\section{REFERENCES}

[1] G. P. Pandey, S. A. Hashmi, J. Power Sources. 187, 627, (2009)

[2] Y.N. NuLi, J. Yang, R.Wu, Electrochem. Commun. 7, 1105, (2005)

[3] G.T. Cheek, W.E. O'Grady, A S.Z. bedin, E.M. Moustafa, F. Endres, J. Electrochem. Soc. 155, D91, (2008)

[4] N. Amir, Y. Vestfrid, O. Chusid, Y. Gofer, D. Aurbach, J. Power Sources. 174, 1234, (2007)

[5] N. Yoshimoto, Y. Tomonaga, M. Ishikawa, M. Morita, Electrochimica Acta. 46, 1195, (2001)

[6] M. Moritaa, T. Shirai, N. Yoshimotoa, I.M. shikawa, J. Power Sources. 139, 351, (2005)

[7] A.P. Abbott, G. Capper, D.L. Davies, H.L. Munro, R.K. Rasheed, V. Tambyrajah, Chem. Commun. 2010, (2001)

[8] A.P. Abbott, K.J. McKenzie, Phys. Chem. Chem. Phys. 8, 4265, (2006)

[9] A.P. Abbott, G. Capper, D.L. Davies, R.K. Rasheed, Chem. Commun. 70, (2003)

[10] Frank E, Abedin S, Phys. Chem. Chem. Phys. 8, 2101, (2006)

[11] S.J. Zhang, X.M. Liu, X.Q. Yao, H.F. Dong, X.P. Zhang, SCIENCE CHINA, B. 39 (10), 1134, (2009) 
[12] A.P. Abbott, G. Capper, K.J. McKenzie, K.S. Ryder, J. Electroanal.Chem. 599, 288, (2007)

[13] Y. Zou, H.J. Xu, G.Z. Wu, Z. Jiang, S.M. Chen, Y.Y. Huang, W. Huang, X.J. Wei, J. Phys. Chem. B 113, 2066(2009)

[14] A.P. Abbott, G. Capper, D.L. Davies, R.K. Rasheed, Chem. Eur. J. 10, 37, $69,(2004)$

[15] A.P. Abbott, Chem.Phys.Chem. 5, 1242, (2004)
[16] J.O'M. Bockris, A.K.N. Reddy, Modern Electrochemistry Vol. 1, Plenum, New York Chapter 61970

[17] G. J. Janz, Molten Salt Handbook, Academic Press, New York 1967

[18] A.P. Abbott, R.C. Harris, K.S. Ryder, J. Phys. Chem. B. 111, 4910, (2007)

[19] M.A. Kareem, F.S. Mjalli, M.A. Hashim, I.M. AlNashe, J. Chem. Eng. Data., Vol. 55(11), 4632, (2010) 